\title{
Differential expression of genes encoding proteins of the HGF/MET system in insulinomas
}

\author{
Cahuê De Bernardis Murat', Paula Waki Lopes da Rosa', Maria Angela Henriques Zanella Fortes', \\ Luciana Corrêa ${ }^{2}$, Marcel Cerqueira Cesar Machado ${ }^{3}$, Estela Maria Novak ${ }^{4}$, Sheila Aparecida Coelho Siqueira ${ }^{5}$, \\ Maria Adelaide Albergaria Pereira ${ }^{6}$, Maria Lucia Corrêa-Giannella ${ }^{1,7}$, Daniel Giannella-Neto ${ }^{8}$ \\ and Ricardo Rodrigues Giorgi ${ }^{1,9^{*}}$
}

\begin{abstract}
Background: Insulinomas are the most common functional pancreatic neuroendocrine tumors, whereas histopathological features do not predict their biological behaviour. In an attempt to better understand the molecular processes involved in the tumorigenesis of islet beta cells, the present study evaluated the expression of genes belonging to the hepatocyte growth factor and its receptor (HGF/MET) system, namely, MET, HGF; HGFAC and ST14 (encode HGF activator and matriptase, respectively, two serine proteases that catalyze conversion of pro-HGF to active HGF); and SPINT1 and SPINT2 (encode serine peptidase inhibitors Kunitz type 1 and type 2, respectively, two inhibitors of HGF activator and of matriptase).
\end{abstract}

Methods: Quantitative real-time reverse transcriptase polymerase chain reaction was employed to assess RNA expression of the target genes in 24 sporadic insulinomas: 15 grade 1 (G1), six grade 2 (G2) and three hepatic metastases. Somatic mutations of MET gene were searched by direct sequencing of exons 2, 10, 14, 16, 17 and 19.

Results: Overexpression of MET was observed in the three hepatic metastases concomitantly with upregulation of the genes encoding HGF and matriptase and downregulation of SPINT1. A positive correlation was observed between MET RNA expression and Ki-67 proliferation index while a negative correlation was detected between SPINT1 expression and the mitotic index. No somatic mutations were found in MET gene.

Conclusion: The final effect of the increased expression of HGF, its activator (matriptase) and its specific receptor (MET) together with a decreased expression of one potent inhibitor of matriptase (SPINT1) is probably a contribution to tumoral progression and metastatization in insulinomas.

Keywords: Insulinoma, Hepatocyte growth factor, MET receptor, Gene expression, Somatic mutation

\section{Background}

Insulinomas are the most common functional pancreatic neuroendocrine tumors (pNETs) with an estimated incidence of 0.4 per 100,000 person-years [1]. They are usually benign, small, solitary and sporadic and are classified

\footnotetext{
*Correspondence: rrgiorgi2@hotmail.com

${ }^{1}$ Laboratório de Endocrinologia Celular e Molecular (LIM-25) do Hospital das Clínicas da Faculdade de Medicina da Universidade de São Paulo (HCFMUSP), Av. Dr. Arnaldo, 455, 01246-903 São Paulo, SP, Brazil

Full list of author information is available at the end of the article
}

as malignant in the presence of local invasion or distant metastases, whereas histopathological features do not predict their biological behaviour [2].

Several studies have reported molecular alterations in the system comprising hepatocyte growth factor (HGF) and its tyrosine kinase receptor MET (HGF/MET system) in different types of neoplasias [3, 4], in which inappropriate MET activation enhances proliferation, anti-apoptotic events, invasiveness and metastatization $[5,6]$. The HGF/MET system has not been systematically investigated in insulinomas. 
In an attempt to better understand the molecular processes involved in the tumorigenesis of islet beta cells, the aim of the present study was to assess the mRNA expression of genes belonging to the HGF/MET system in sporadic insulinomas and to correlate the expression findings with histopathological characteristics of the tumors. Besides $M E T$ and $H G F$, we also evaluated mRNA expression of the following components: (1) HGFAC and $S T 14$, that encode HGF activator and matriptase, respectively, two serine proteases that catalyze conversion of pro-HGF to active HGF and (2) SPINT1 and SPINT2, that encode serine peptidase inhibitors Kunitz type 1 and type 2, respectively, two potent inhibitors of HGF activator and of matriptase. To evaluate possible mechanisms involved in MET overexpression, the presence of somatic mutations in this gene was also examined.

\section{Methods}

\section{Patients and tissue specimens}

Tissue collection was performed in compliance with the Institutional Ethics Committee (CAPPesq) and in accordance to the Declaration of Helsinki, with informed consent being required from each subject. From 1999 to 2011, 24 tumor tissues were obtained and processed as previously described [7]. Tumor fragments were collected in sterile containers and immediately frozen in liquid nitrogen. The tumors were graded according to the classification system recommended by the European Neuroendocrine Tumor Society (ENETS) and the World Health Organization (WHO): (1) well-differentiated grade 1 neuroendocrine tumor (G1; $<2$ mitoses/10 HPF [high-power fields] and $<3 \% \mathrm{Ki}-67$ index); (2) welldifferentiated grade 2 neuroendocrine tumor (G2; 2-20 mitoses/10HPF or 3-20 \% Ki-67 index) and; (3) poordifferentiated grade 3 neuroendocrine carcinoma (G3; $>20$ mitoses/10HPF or $>20 \% \mathrm{Ki}-67$ index) [8]. The histopathological characteristics of these insulinomas are shown in Additional file 1: Table S1. The present series consisted of 15 G1 insulinomas, six G2 insulinomas and three hepatic metastases.

\section{Quantitative real-time reverse transcriptase polymerase chain reaction (qRT-PCR)}

Total RNA was extracted using the TriZol reagent (Invitrogen, Carlsbad, CA, USA) according to the manufacturer's recommendations. RNA integrity and quantity were evaluated using the RNA 6000 Nano Assay with the Agilent 2100 Bioanalyzer (Agilent Technologies, Palo Alto, CA, USA) and only samples with an RNA Integrity Number (RIN) $>7$ were used. Complementary DNA (cDNA) was synthesized from total RNA. Briefly, first-strand cDNA synthesis was carried out with $1 \mu \mathrm{g}$ of RNA, $1 \mu \mathrm{L}$ of oligo(dT) primers $(0.5 \mu \mathrm{g} / \mu \mathrm{L}), 1 \mu \mathrm{L}$ of a solution with all four deoxyribonucleoside triphosphates (each at $10 \mathrm{mM}$ ), and $10 \times$ Superscript III reverse transcriptase (Invitrogen).

For TaqMan-based qRT-PCR, 100 ng of cDNA was added to $10 \mu \mathrm{L}$ of $2 \times$ Universal PCR Master Mix and to $1 \mu \mathrm{L}$ of $20 \times$ the specific primers and probe set (Applied Biosystems, Carlsbad, CA, USA). Fifty cycles of amplification were performed at $95{ }^{\circ} \mathrm{C}(15 \mathrm{~s})$ and $60{ }^{\circ} \mathrm{C}(1 \mathrm{~min})$ in a StepOne Plus Realtime PCR system (Applied Biosystem). The following Assay on Demand primers and probes were used: Hs00300159_m1 (HGF), Hs01565584_m1 (MET), Hs00173526_m1 (HGFAC), Hs01058386_m1 (ST14), Hs00173678_m1 (SPINT1), Hs01070442_m1 (SPINT2) and Hs01652481_g1 (PSMC6, which encodes the proteasome 26S subunit, ATPase, 6) used as a control endogenous gene, as previously validated [7]. Human liver cDNA was used as positive control for HGF, MET, HGFAC and ST14 genes expression and human placental tissue was used as a positive control for SPINT1 and SPINT2 genes expression. All samples were run in triplicate. Gene expression levels were analyzed by the mathematical model variation described by Livak and Schmittgen [9], $2^{-\Delta \mathrm{Ct}}[10]$.

\section{Mutational analysis}

DNA from tumoral samples was extracted using the DNeasy kit (Qiagen, Valencia, CA, USA) according to the manufacturer's instructions. For mutational analyses, exons 2, 10, 14, 16, 17 and 19 of MET proto-oncogene (GenBank accession number NM_000245) were amplified with specific primers (designed using the Primer 3 software) for direct sequencing on an ABI 3130X Genetic Analyzer (Applied Biosystems) in $50 \mu$ l of PCR reaction mixture [100 ng genomic DNA, $0.2 \mathrm{mM}$ of each primer, $200 \mu \mathrm{M}$ deoxynucleotides, $1 \times$ buffer and 1 U DNA Taq polymerase (GE Healthcare, Salt Lake City, UT, USA)]. PCR products were purified with ExoSAP IT (USB, Cleveland, OH, USA) and sequenced using the BigDye Terminator v1.1 Cycle Sequencing Kit (Applied Biosystems). Cycling conditions were as follows: $95{ }^{\circ} \mathrm{C}$ for $5 \mathrm{~min}, 35$ cycles of $95^{\circ} \mathrm{C}$ for $30 \mathrm{~s}$, followed by $56{ }^{\circ} \mathrm{C}$ (all exons) for $30 \mathrm{~s}$ and $72{ }^{\circ} \mathrm{C}$ for $10 \mathrm{~min}$ in a Thermocycler Model Veriti (Applied Biosystems). The sequences were analyzed using the Sequencher software, version 4.10.1.

\section{Statistical analysis}

Statistical tests were performed with JMP Version 10 statistical computer program (SAS Institute, Cary, NC, USA). Data were evaluated by Kruskal-Wallis test followed by Dunn's multiple comparisons test. Analyses of correlations between the values of each gene expression and histopathological features were performed with the 
Spearman correlation test. Statistical significance was fixed at probability levels of $<0.05$.

\section{Results}

\section{Gene expression by qRT-PCR}

As shown in Fig. 1, a higher expression of $M E T$ $(P=0.0115$, Panel A), HGF $(P=0.0183$, Panel $\mathrm{B})$ and ST14 $(P=0.0453$, Panel $C)$ mRNA was observed in the three metastases in comparison to G1 insulinomas. No HGFAC gene expression was detected in any studied tumoral sample (data not shown). The expression of SPINT1 mRNA (Panel D) was lower in the three metastases in comparison to G1 insulinomas $(P=0.0250)$, whereas no difference was detected in SPINT2 gene expression (Panel E). No statistically significant differences were observed between G1 and G2 insulinomas for any of the studied genes.

Additional file 2: Table S2 depicts the statistically significant correlations observed between tumoral histopathological variables and mRNA expression of the studied genes and also the correlations found among mRNA expression of the target genes. A positive correlation was observed between $M E T$ mRNA expression and Ki-67 proliferation index $(\rho=0.4682 ; P=0.0210)$ while a negative correlation was detected between SPINT1 mRNA expression and the mitotic index $(\rho=-0.4721$; $P=0.0174)$. High positive correlations were found between $M E T$ and $H G F$ mRNA expression $(\rho=0.7827$; $P<0.0001)$ and between $M E T$ and ST14 mRNA expres$\operatorname{sion}(\rho=0.8272 ; P<0.0001)$.

\section{MET mutation analysis}

Direct sequencing of the exons previously found mutated in other neoplasias $(2,10,14,16,17$ and 19) did not reveal somatic mutations in the $M E T$ gene in any tumoral sample.

\section{Discussion}

This study demonstrated the differential expression of four genes belonging to the HGF/MET system between G1 insulinomas and liver metastases of insulinomas, suggesting the participation of this pathway in the later stages of tumorigenesis.

The final effect of the increased expression of a growth factor (HGF), one of its activator (ST14) from the precursor molecule and its specific receptor (MET) together with a decreased expression of one potent inhibitor of the growth factor activator (SPINT1) is probably a contribution to tumoral progression, which is consistent with findings in other human neoplasias. In pancreatic carcinoma cells, HGF seems to have a potent role in invasion and metastasis by exerting its antianoikis effect through phosphatidylinositol 3-kinase pathway [11]. In gastric cancers, for instance, the high expression of $M E T$ and $H G F$ is associated with the development of metastases [12].

Findings that corroborate this hypothesis are the positive correlations observed between MET RNA expression and the Ki-67 proliferative index as well as the negative correlation between SPINT1 expression and the mitotic index. The correlations found among the RNA expression of the studied genes suggest interdependence among the different proteins that comprise the HGF/MET system.

In contrast to our findings, Wulbrand et al. [13] did not detect the expression of MET in ten insulinomas. However, only one case was described as metastatic and the methodology employed (RT-PCR) is less sensitive that the qRT-PCR used in the present study. Hansel et al. [14] have previously described increased expression of MET in metastatic versus non-metastatic pNETs, as well as in lymph node and in liver metastases, but their series did not include any metastatic insulinoma, only non-functioning tumors, glucagonomas and gastrinomas. These data suggest that overexpression of MET is a molecular marker of malignancy not only of insulinomas, but also of other pNETs.

Activating mutations in the $M E T$ gene can promote the hyperactivity of this signalling pathway [15]. The following main oncogenic mutations have been described for this gene [4]: point mutations that lead to an alternative splicing, which results in a small protein without a PKC (protein kinase C) binding degradation site [16]; point mutations in the tyrosine kinase domain, which maintain the receptor constitutively active [17], and mutations that inactivate the negative regulatory $\mathrm{Cbl}$ (E3 ubiquitin protein ligase) binding site, which drive MET to ubiquitination, endocytosis, and subsequent degradation [18].

To investigate whether the presence of somatic mutations would be involved in $M E T$ upregulation, direct sequencing of exons previously reported as mutated in other cancer types was performed and no mutations were detected. Alternative explanations for the observed MET overexpression could be gene amplification, as reported in non-small-cell lung carcinoma [19] and in ovarian adenocarcinoma [20], gains of 7q (MET gene is located on $7 \mathrm{q} 31$ ) that are known to be involved in the progression of insulinomas and other pNETs [21], and epigenetic modifications, such as loss of DNA methylation, already identified in a mouse model of hepatocellular carcinoma [22].

An interesting finding of the present study was the absence of RNA expression of HGFAC, considered the most powerful activator of pro-HGF in HGF [23], indicating that in insulinomas, matriptase (and maybe other proteins not evaluated in this study, such as hepsin [24] ) is responsible for pro-HGF proteolysis. A lower RNA 


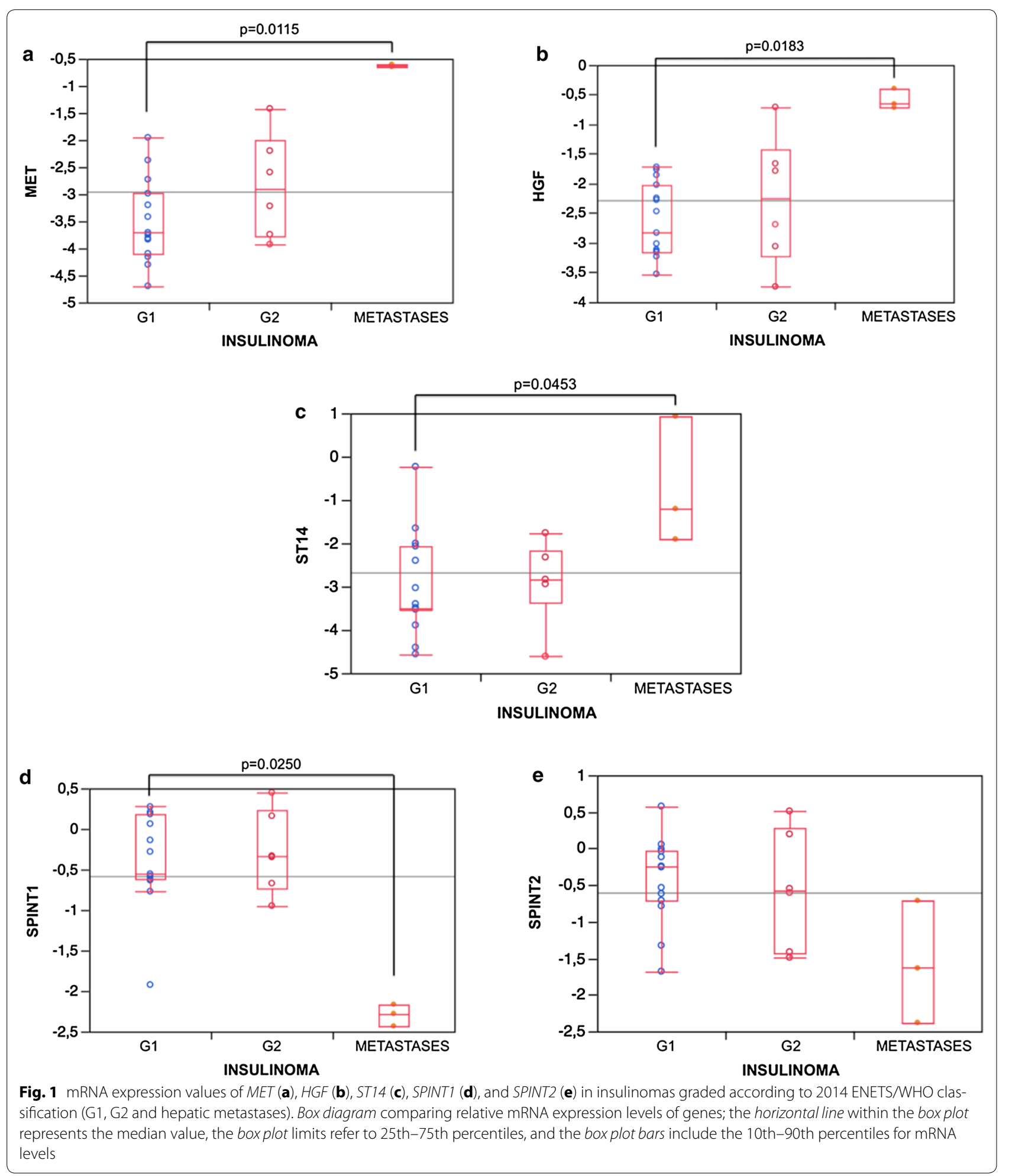

expression of the inhibitor of matriptase SPINT1 was detected in the insulinoma metastases, potentially contributing to increased activity of matriptase to participate in HGF activation.
The main limitation of this study is the small number of metastasis samples, due to the rarity of this condition. Nevertheless, the differential expression of not only one but four different genes of HGF/MET system, the 
observed correlations between MET and SPINT1 mRNA expression and tumor histopathological features and the previous identification of MET as overexpressed in other metastatic pNETs [14] suggest the participation of the HGF/MET pathway in the later stages of insulinoma tumorigenesis. The confirmation of our findings in larger series could allow the development of strategies oriented to this system as a potential target to control the progression of insulinomas.

\section{Additional files}

Additional file 1: Table S1. Summary of patient's demographic data and tumor histopathological features of the 24 insulinomas.

Additional file 2: Table S2. Statistically significant correlations among RNA expression of the studied genes and tumoral histopathological variables.

\section{Authors' contributions}

CBM performed most of the experiments with the help of PWLR and MAHZF; $L C$ and MAAP critically revised the manuscript and made many conceptual suggestions; MCCM performed the surgical procedures and provided the tumoral samples; EMN contributed with reagents, materials and analysis tools; SACS the histopathological analyses; MLCG co-designed the study and cowrote the manuscript; DGN performed statistical analysis and RRG obtained funding, co-designed the study and co-wrote the manuscript. All authors read and approved the final manuscript

\section{Author details}

${ }^{1}$ Laboratório de Endocrinologia Celular e Molecular (LIM-25) do Hospital das Clínicas da Faculdade de Medicina da Universidade de São Paulo (HC-FMUSP), Av. Dr. Arnaldo, 455, 01246-903 São Paulo, SP, Brazil. Departamento de Patologia Oral, Faculdade de Odontologia da Universidade de São Paulo, São Paulo, Brazil. ${ }^{3}$ Laboratório de Emergências Clínicas (LIM-51) da FMUSP, São Paulo, Brazil. ${ }^{4}$ Laboratório de Biologia Molecular da Fundação Pró-Sangue Hemocentro de São Paulo, São Paulo, Brazil. ${ }^{5}$ Divisão de Patologia do HC-FMUSP, São Paulo, Brazil. ${ }^{6}$ Divisão de Endocrinologia do HC-FMUSP, São Paulo, Brazil. ${ }^{7}$ Centro de Terapia Celular e Molecular (NUCEL/NETCEM) da FMUSP, São Paulo, Brazil. ${ }^{8}$ Programa de Pós-Graduação em Medicina, Universidade Nove de JulhoUNINOVE, São Paulo, Brazil. ${ }^{9}$ Programa de Pós Graduação em Ciências da Saúde, Universidade de Santo Amaro (UNISA), São Paulo, Brazil.

\section{Compliance with ethical guidelines}

\section{Competing interests}

The authors declare that they have no competing interests.

Received: 9 February 2015 Accepted: 22 September 2015 Published online: 01 October 2015

\section{References}

1. Service FJ, McMahon MM, O'Brien PC, Ballard DJ. Functioning insulinomaincidence, recurrence, and long-term survival of patients: a 60-year study. Mayo Clin Proc. 1991;66:711-9.

2. Grant CS. Insulinoma. Best Pract Res Clin Gastroenterol. 2005;19:783-98.

3. Trusolino L, Bertotti A, Comoglio PM. MET signalling: principles and functions in development, organ regeneration and cancer. Nat Rev Mol Cell Biol. 2010;11:834-48.

4. Sierra JR, Tsao MS. C-MET as a potential therapeutic target and biomarker in cancer. Ther Adv Med Oncol. 2011;3:S21-35.

5. Danilkovitch-Miagkova A, Zbar B. Dysregulation of Met receptor tyrosine kinase activity in invasive tumors. J Clin Investig. 2002;109:863-7.
6. Benvenuti S, Comoglio PM. The MET receptor tyrosine kinase in invasion and metastasis. J Cell Physiol. 2007;213:316-25.

7. de Sa SV, Correa-Giannella ML, Machado MC, Krogh K, de Almeida MQ, Albergaria Pereira MA, Coelho Siqueira SA, Patzina RA, Ibuki FS, Sogayar $M C$, et al. Serpin peptidase inhibitor clade A member 1 as a potential marker for malignancy in insulinomas. Clin Cancer Res Off J Am Assoc Cancer Res. 2007:13:5322-30.

8. Klimstra DS, Modlin IR, Coppola D, Lloyd RV, Suster S. The pathologic classification of neuroendocrine tumors: a review of nomenclature, grading, and staging systems. Pancreas. 2010;39:707-12.

9. Livak KJ, Schmittgen TD. Analysis of relative gene expression data using real-time quantitative PCR and the 2(-Delta Delta C(T)) Method. Methods. 2001;25:402-8.

10. Lattuada D, Vigano P, Mangioni S, Sassone J, Di Francesco S, Vignali $M$, Di Blasio AM. Accumulation of retinoid $X$ receptor-alpha in uterine leiomyomas is associated with a delayed ligand-dependent proteasomemediated degradation and an alteration of its transcriptional activity. Mol Endocrinol. 2007;21:602-12.

11. Watanabe S, Kishimoto T, Yokosuka O. Hepatocyte growth factor inhibits anoikis of pancreatic carcinoma cells through phosphatidylinositol 3-kinase pathway. Pancreas. 2011;40:608-14.

12. Zhang QH, Qian K, Li XJ, Pu J, Wu XT. Experimental study of the hepatocyte growth factor contributing to lymphangiogenesis and lymphatic metastasis in gastric cancer. Zhonghua wei chang wai ke za zhi Chin J Gastrointest Surg. 2007;10:212-6.

13. Wulbrand U, Wied M, Zofel P, Goke B, Arnold R, Fehmann H. Growth factor receptor expression in human gastroenteropancreatic neuroendocrine tumours. Eur J Clin Invest. 1998;28:1038-49.

14. Hansel DE, Rahman A, House M, Ashfaq R, Berg K, Yeo CJ, Maitra A. Met proto-oncogene and insulin-like growth factor binding protein 3 overexpression correlates with metastatic ability in well-differentiated pancreatic endocrine neoplasms. Clin Cancer Res Off J Am Assoc Cancer Res. 2004;10:6152-8.

15. Clague MJ. Met receptor: a moving target. Sci Signal. 2011;4:pe40.

16. Lutterbach B, Zeng Q, Davis LJ, Hatch H, Hang G, Kohl NE, Gibbs JB, Pan BS. Lung cancer cell lines harboring MET gene amplification are dependent on Met for growth and survival. Cancer Res. 2007;67:2081-8.

17. Giordano S, Maffe A, Williams TA, Artigiani S, Gual P, Bardelli A, Basilico C, Michieli P, Comoglio PM. Different point mutations in the met oncogene elicit distinct biological properties. FASEB J Off Publ Fed Am Soc Exp Biol. 2000;14:399-406.

18. Kong-Beltran M, Seshagiri S, Zha J, Zhu W, Bhawe K, Mendoza N, Holcomb T, Pujara K, Stinson J, Fu L, et al. Somatic mutations lead to an oncogenic deletion of met in lung cancer. Cancer Res. 2006;66:283-9.

19. Go H, Jeon YK, Park HJ, Sung SW, Seo JW, Chung DH. High MET gene copy number leads to shorter survival in patients with non-small cell lung cancer. J Thorac Oncol Off Publ Int Assoc Study Lung Cancer. 2010;5:305-13.

20. Yamamoto S, Tsuda H, Miyai K, Takano M, Tamai S, Matsubara O. Gene amplification and protein overexpression of MET are common events in ovarian clear-cell adenocarcinoma: their roles in tumor progression and prognostication of the patient. Modern Pathol Off J USA Can Acad Pathol Inc. 2011;24:1146-55.

21. Speel EJ, Richter J, Moch H, Egenter C, Saremaslani P, Rutimann K, Zhao J, Barghorn A, Roth J, Heitz PU, Komminoth P. Genetic differences in endocrine pancreatic tumor subtypes detected by comparative genomic hybridization. Am J Pathol. 1999;155:1787-94.

22. Ogunwobi OO, Puszyk W, Dong HJ, Liu C. Epigenetic upregulation of HGF and c-Met drives metastasis in hepatocellular carcinoma. PLoS One. 2013;8:e63765.

23. Kataoka H, Miyata S, Uchinokura S, Itoh H. Roles of hepatocyte growth factor (HGF) activator and HGF activator inhibitor in the pericellular activation of HGF/scatter factor. Cancer Metastasis Rev. 2003;22:223-36.

24. Kirchhofer D, Peek M, Lipari MT, Billeci K, Fan B, Moran P. Hepsin activates pro-hepatocyte growth factor and is inhibited by hepatocyte growth factor activator inhibitor-1B (HAI-1B) and HAl-2. FEBS Lett. 2005;579:1945-50. 